\title{
La Magdalena Penitente de Mateo Cerezo, perteneciente a la colección de Aureliano de Beruete, localizada de nuevo en una colección madrileña
}

Susana Fernández de Miguel

Investigadora vinculada a la Universidad de Málaga

RESUMEN

La localización, en la "Colección Granados" de Madrid, de un cuadro representando una "Magdalena Penitente" de la mano del pintor Mateo Cerezo, y su identificación como una obra perteneciente al coleccionista español Don Aureliano de Beruete, sirve de punto de partida, para el estudio de la representación iconográfica de la santa, su tratamiento y versiones en la obra del pintor, las réplicas, sus diferencias estilísticas y técnicas, datación y las vicisitudes atravesadas por la pintura.

PALABRAS CLAVE: Iconografía mariana/ Pintura s. XVII/Coleccionismo/ Tratadística/ Madrid.

"Mary Magdalene as a Penitent" by Mateo Cerezo belonging to Aureliano of Beruete's Collection, located again into a Madrilenian Collection.

ABSTRACT

The location in the madrilenian "Granados Collection" of a picture representing a "Penitent Magdalen" of the painter Mateo Cerezo and it identification as the work belonged to the spanish collector Mr. Aureliano de Beruete, is used as point of item, for the study of the iconographic representation of the saint, her treatment and versions in the work of the painter, the replies, its stylistic and technical differences, dating and, finally, the vicissitudes suffered by the painting.

KEY WORDS: Virgin's Iconography/ Painting XVII th/ Art Collection/ Treatise books/ Madrid.

No hace mucho tiempo, tuve la oportunidad de acceder a una de las actuales colecciones madrileñas de arte antiguo, la de Don Miguel Granados, buen conocedor y probado amante de la pintura, principalmente del siglo XVII español.

Entre las obras que integraban la colección, se encontraba una "Magdalena Penitente". El estudio de sus características y técnica pictórica nos llevó a concluir que estábamos ante una de las buenas obras de Mateo Cerezo [1], que además presentaba la curiosidad de dos viejas etiquetas pegadas al dorso, en su bastidor.

La primera de ellas, blanca y sin borde, no muy antigua, perfectamente conservada y legible decía "The Penitent Magdalen (Cerezo) Owner: Don Aureliano de

* FERNÁNDEZ DE MIGUEL, Susana: "La Magdalena Penitente de Matheo Zerezo, perteneciente a la colección de Aureliano de Beruete, localizada de nuevo en una colección madrileña", en Boletín de Arte, $n^{\circ} 29$, Departamento de Historia del Arte, Universidad de Málaga, 2008, págs. 159-171. 


\section{Q: artículos Susana Fernández de Miguel}

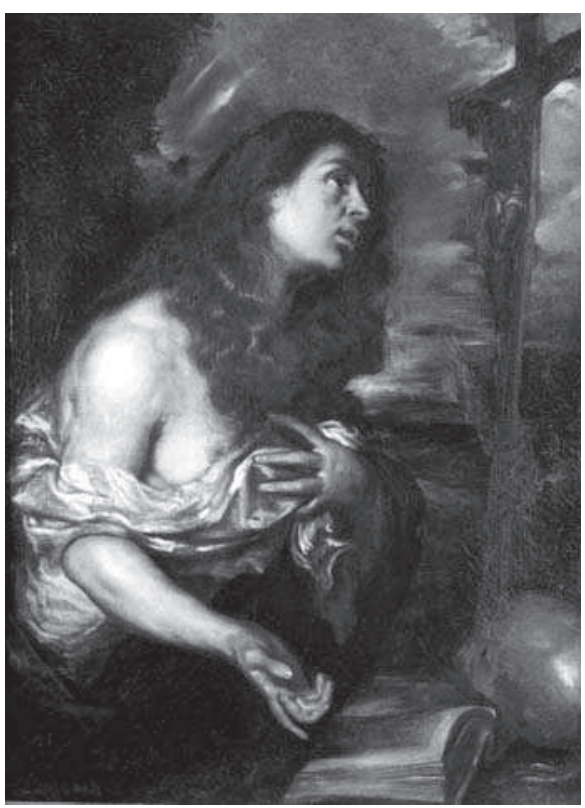

1. Magdalena Penitente, Colección Granados, Madrid.

Beruete y Moret Cat. № 169 [2]. La segunda contenía otra numeración: "961" [3].

De los datos proporcionados por las etiquetas, se deduce que la pintura no era otra que la "Magdalena Penitente", que había pertenecido al pintor y coleccionista español, Don Aureliano de Beruete y Moret, incluida en su inventario de pinturas, en el ínterin, subastada en Inglaterra y que, azares del destino, la habían retornado a España, país donde vio la luz de la mano de su autor.

Esta es, pues, la historia de una loable recuperación y el pretexto para sumergirnos en el estudio de la iconografía de la santa, la personalidad y obra de Mateo Cerezo, las versiones del tema elegidas por este artista en el contexto de su obra, sus réplicas y la datación de las mismas.

A lo largo del siglo XVII, la doctrina de la Iglesia, frente a las líneas de la Reforma protestante, entendía que las imágenes religiosas eran santas por dos títulos, uno porque estaban consagradas a Dios y otro porque le representaban a Él o a su Corte. A este último grupo pertenecían las imágenes de los Santos, a los que consideraban como "los criados a su casa y grandes de su Corte", como afirmaba el Padre jesuita Martín de Roa, en los escritos doctrinales que publicó en Sevilla ${ }^{1}$, dirigidos a la difusión y enseñanza de la doctrina católica en materia iconológica.

Estos conceptos eran el reflejo de la doctrina impuesta por el Concilio de

${ }^{1}$ ROA, M. de: Antigüedad Veneración i Fruto de las Sagradas Imágenes i Reliquias. Sevilla 1623, pág. 86. 


\section{D artículos La Magdalena Penitente de Mateo Cerezo...}
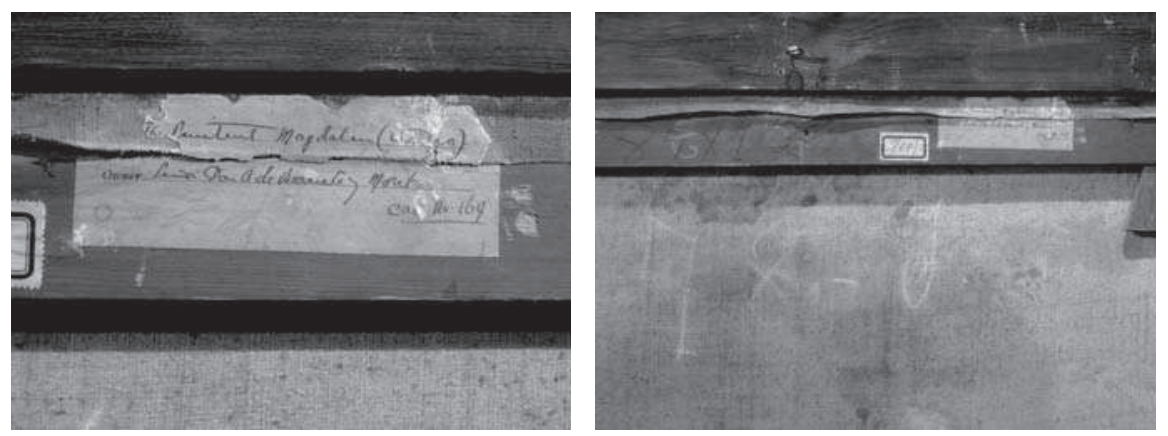

2. y 3. Etiqueta núm. 1, inserta en el bastidor de la pintura.

Trento, en su Sesión XXV, que enseñaba que, si había que dar honra y veneración a las imágenes, no era porque se entendiera que en ellas había alguna excelencia digna de honra, sino porque la tenían las personas a las que representaban ${ }^{2}$ y porque, a través de ellas, los fieles se dirigían al mismo Dios.

Los principios de representación de los santos quedaron fijados el 3 de Diciembre de 1563 en el Decreto "De invocatione, veneratione et reliquiis sanctorum et de sacris imaginibus"3. A partir de ese momento se sucedieron los tratados teóricos que facilitaron a los artistas la definición de la iconografía religiosa, concretando los criterios a los que debía obedecer la correcta aplicación de las enseñanzas eclesiásticas.

La representación de María Magdalena no fue una excepción, facilitándose desde la misma Iglesia y los tratadistas las consignas concretas en cuanto a la forma en que ésta debía ser representada.

Vicente Carducho en su obra Diálogos de la Pintura4 planteó el tema del "decoro", tanto en su dimensión de representación adecuada o conveniente de algo, preocupación típicamente renacentista, como en su dimensión moralizante y religiosa y se refiere también al obligado repudio a las representaciones de santidad excesivas en elementos mundanos o cotidianos. Así, aludiendo al pasaje de la visita de Jesús a las hermanas de Lázaro, considera no ajustado al "decoro" la representación de los personajes rodeados con profusión de todo tipo de aves, frutas y viandas en general, que califica como más propias de una escena de cocina o de la representación del vicio de la "gula", pero no de escenas de devoción ${ }^{5}$.

2 Ibídem., págs. 87 -87 vto. “... son cosas que tocan a Dios i a sus Santos y la onra que a la Imagen se hace, passa a la persona de quien es la imagen, i por ultimo termino al mismo Dios Autor de toda Santidad i excelencia".

3 Cfr. Conc. Tridentinum, Decretum de invocatione, veneratione et reliquiis Sanctorum, et sacris imaginibus, 3- XII-1563: Denz - Schön, 1821.

4 CARDUCHO, V.: Diálogos de la Pintura, su defensa, origen, esencia, definición, modos y diferencias, Madrid, 1633. 


\section{2: artículos Susana Fernández de Miguel}

Francisco Pacheco dedicó un capítulo completo de su tratado al estudio de las normas a seguir por los pintores en la representación de personajes religiosos y de los santos, que tituló "De advertencias importantes en algunas historias sagradas acerca de la verdad y acierto con que se deben pintar conforme a la Escritura Divina y Santos Dotores"6. En este capítulo aunque no llega a tratar de manera específica los principios a los que debía obedecer la representación de la Magdalena, sí insistió, sin embargo, en el principio general de que el pintor debía sujetarse a la doctrina de la Iglesia a la hora de pintar las historias sagradas.

Las normas aceptadas comúnmente por la Iglesia y sus tratadistas del barroco, imponían la representación de "María Magdalena", con la cabellera suelta, caída sobre los hombros, y con lágrimas en el rostro, ya que con ellos había enjugado los pies de Jesús después de perfumarlos, recordando así su vida de pecado y posterior arrepentimiento. La imagen debía presentar siempre un aspecto austero, aunque se permitía cierta desnudez, siempre que no traspasara los límites del "decoro". Para la mejor identificación de la representación, las imágenes se acompañaban de los atributos significativos de la personalidad del santo, reservándose a la Magdalena un concreto repertorio.

Dentro de los compartidos con otros santos nos encontramos con el nimbo o la aureola, que aunque era un antecedente del paganismo, por el arrepentimiento, se transformaba en signo de santidad y, dentro de los específicos, con el frasco de perfume.

A lo largo de los siglos XVI y XVII se le añaden otros nuevos símbolos, menos espirituales y más mundanos al objeto de embellecer el resultado pictórico, aunque éstos siempre debían estar presentados en forma negativa, de rechazo y de renuncia a la vida de pecado y, en general, al mundo. Estos nuevos símbolos suponían la representación de objetos cotidianos relacionados con el lujo, fundamentalmente las joyas, que, siguiendo los criterios impuestos, aparecían arrancadas y esparcidas por el suelo, teniendo como antecedente la "Conversione" en el repertorio de Caesare Ripae7.

También le eran inherentes los símbolos de la más grave devoción : "la calavera", como símbolo de penitencia y rechazo a la vanidad mundana; "el crucifijo", como símbolo del amor a Cristo, "el libro", como símbolo de sabiduría, rechazo del pecado y abrazo del amor de Dios y "la naturaleza", rodeando la santa, como símbolo de abandono de la vida terrenal.

\footnotetext{
5 Ibídem., Diálogo Séptimo: De las diferencias y modos de pintar los sucesos e historias sagradas con la decencia que se debe.

“... que también es justo se repare en otras Pinturas de devoción, pintadas con tanta profundidad, y desacato, que apenas se conoce: y vi los días pasados pintar a aquella santa visita de Christo a las hermanas de Lázaro, la devota Magdalena, y la solícita Marta, cercados todos con tanta prevención de comida, de carnero, capones, pavos, fruta, platos, y otros instrumentos de cocina, que más parecía hostería de la gula, que hospicio de santidad, y de cuidadosa fineza, y me espanto de la poca cordura del Pintor, que tal obra saca de su idea y manos."

6 PACHECO, F.: Arte de la Pintura, su antigüedad y grandezas. Sevilla (1649), Cáp. IX.: "Aunque parece que queda bastantemente encarecida, en muchas partes de estos libros, la puntualidad que se debe guardar en pintar la sagradas historias conforme fueren dictadas por el Espíritu Santo, y los Dotores santos las declaran, no serán sobradas las advertencias propuestas; en especial a los artífices menos inteligentes (porque los más capaces no sólo aman la libertad, pero sacuden, con impaciencia, el yugo de la razón."

7 RIPAE, C.: Iconología. Milán, 1602.
} 


\section{2: artículos La Magdalena Penitente de Mateo Cerezo...}

En cuanto a la actitud, los pintores siguieron generalmente el repertorio de la "Oración" de Caesare Ripae, representando generalmente a María Magdalena llevándose la mano derecha al pecho, a la altura del corazón, como símbolo de sinceridad y entrega espiritual, con el antebrazo apoyado en una roca o en un libro y la barbilla sobre la mano, en actitud de meditación o melancolía.

La abundancia de estos tratados de iconología varias veces reeditados y sus traducciones en todos los idiomas europeos, prueban que éstos formaban parte de la cultura general de los artistas, como también de la de su clientela. Los artistas españoles de la época también atesoraron abundantes conocimientos iconológicos, adquiridos a través de los numerosos grabados y libros de la materia que, desde mediados del siglo XVI, habían circulado en nuestro país, llegados del exterior, lo que les permitió un extenso repertorio representativo.

Las representaciones de la Magdalena abundaron en el siglo XVII como vía idónea para la representación del éxtasis espiritual y del arrepentimiento, plasmación que incitaba la superación del artista para, a través de la expresión del personaje, transmitir a su clientela ese estado de ánimo superior, de indudable dificultad y reservada su consecución únicamente a los virtuosos.

Uno de los temas pictóricos más recurrentes en Mateo Cerezo fue, precisamente, la representación de la "Magdalena". El artista no se limitó a imitar otras versiones anteriores o coetáneas, sino que creó unas propias y específicas, que tuvieron tanta aceptación dentro de su producción, que de ellas realizó numerosas réplicas, de las que sólo algunas han llegado hasta nuestros días.

Hasta la monografía que, en 1986, le dedicaron los historiadores José Buendía e Ismael Gutiérrez Pastor ${ }^{8}$, sólamente disponíamos de los antecedentes biográficos que del pintor había proporcionado Antonio Palomino ${ }^{9}$ y las adiciones posteriores realizadas por el historiador Elías Tormo ${ }^{10}$, que, aunque fueron el anuncio de una monografía, ésta nunca llegó a ver la luz.

Después de la citada monografía, el profesor Alfonso Pérez Sánchez efectuó una serie de "matizaciones" a la misma ${ }^{11}$, a las seguidamente nos referiremos y, por último, distintos autores dedicaron al pintor algunas referencias documentales aisladas.

Antonio Palomino, en su obra, principia la biografía del pintor con su nombre como encabezamiento: "MATHEO CEREZO, pintor". Le afirma natural de Burgos, siendo su padre del mismo nombre, que viaja a Madrid cuando apenas tenía 15 años, entrando en la escuela de Don Juan Carreño, donde continúa sus estudios de pintura, frecuentando las academias, el pintar al natural y la copia de los originales de palacio.

También que, cuando "andaba más de 20 años", ya siendo pintor acreditado

8 BUENDÍA, J. R. y GUTIÉRREZ PASTOR, I.: Vida y Obra del pintor Mateo Cerezo (1637-1666). Burgos, 1986.

9 PALOMINO, A.: El Parnaso español pintoresco laureado, Vida, 145. Madrid, 1724,.

10 TORMO, E.:"Mateo Cerezo", Archivo Español de Arte y Arqueología, n VIII, mayo/agosto, 1927, pág. 113.

11 PÉREZ SÁNCHEZ, A. E.: "Revisión de Mateo Cerezo. A propósito de un libro reciente", en Archivo Español de Arte, nº 60: 239, jul/sep, 1987, pág. 281. 
2: artículos Susana Fernández de Miguel

por sus concepciones y otros "Assumptos Devotos para personas particulares", comenzó su labor pictórica en la corte, ejecutando encargos con destino a las distintas iglesias de Madrid.

La ejecución de las "Magdalenas" obedeció también a la demanda de comitentes particulares, ya que en los inventarios de muchas de las colecciones particulares del siglo XVII se recogen diversas pinturas del artista que representan a la santa penitente.

Buendía y Gutiérrez Pastor amplía su biografía, afirmando durante la estancia del pintor en la Corte, una inicial ausencia de vinculación formativa con ninguno de los talleres establecidos, y su posterior colaboración con Herrera el Mozo en la decoración de la cúpula de la Iglesia de Atocha.

Elías Tormo calificó a Mateo Cerezo como "exquisito pintor y un artista malogrado"12. Consideramos acertadas ambas calificaciones y las mantenemos.

Fue un artista malogrado porque, como otros artistas de la época, falleció a una edad temprana, cuando apenas comenzaba a plasmar sus logros dentro de la pintura y a celebrarse el reconocimiento de su arte. Fue exquisito por la soltura en la pincelada, la composición y el colorido de su obra.

En todo caso destacamos, como evolución en su pintura, la suavidad y elegancia en los modelos, que luego abandona para tornarlos más graves, severos y dramáticos, y las tonalidades matizadas, conseguidas en sus primeras obras madrileñas, que luego endurece, acentuando el contraste y utilizando colores más puros.

Mateo Cerezo como pintor del tema de la Magdalena, fue creador de dos prototipos específicos y personales destinados a satisfacer los gustos de la época, según las diferentes pretensiones y exigencias de los comitentes.

Estos prototipos nos presentan, por un lado a una Magdalena penitente mórbida, exuberante, semidesnuda, de cabellos claros y una representación dulcemente colorista, con predominio de los tonos blancos y azules, dirigida, fundamentalmente, a los amantes de la belleza en la pintura, aunque sin descuidar la referencia religiosa que socialmente se imponía.

El segundo de los prototipos nos presenta a la Magdalena en una actitud de más grave penitencia, tanto en su expresión, como en el gesto, monocroma y tenebrista, con una carga dramática superior, a fin de exacerbar el sentimiento de culpa y contrición de los fieles cristianos, dirigida a los comitentes más severos en los que primaba el sentimiento religioso.

Mateo Cerezo, educado a la luz de los austeros tiempos religiosos de la Contrarreforma, utilizó frecuentemente este tema para sus obras, en las dos versiones mencionadas, con numerosas réplicas de ambas, dada la popularidad alcanzada por la santa a lo largo de estos años.

Elías Tormo recoge la opinión de Theophile Thoré, al que considera uno de los mejores conocedores de la buena pintura a mediados del siglo XIX, que alude a este diferente tratamiento en la representación iconográfica de la Magdalena por

12 TORMO: op. cit., nota 10, pág. 113. 


\section{2: artículos La Magdalena Penitente de Mateo Cerezo...}

4. Magdalena Penitente, Rijksmuseum, Ámsterdam.

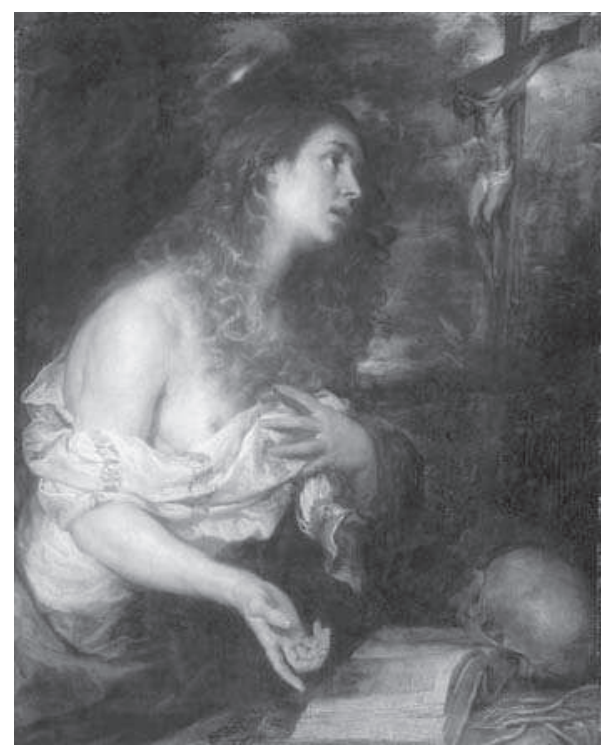

parte de Mateo Cerezo, con el siguiente lamento: "quedaron en España la mayor parte de los cuadros grandes representando la Concepción y la Asunción, pero las rubias Magdalenas han podido ocupar su sitio en las colecciones extranjeras" 13 .

\section{la Magdalena penitente: Obras conocidas y documentadas.}

Antonio Palomino, no cita entre las obras descritas en la biografía del pintor ninguna representación de la Magdalena.

Ceán Bermúdez ${ }^{14}$ cita de su autoría las siguientes:

- "Santa María Magdalena", en la Capilla de Santa Teresa del Convento de los Carmelitas Descalzos de Madrid, de la que Elías Tormo afirmaría después estar en ignorado paradero.

- "Magdalena", de la Catedral de Badajoz, de cuerpo entero, en su altar, que no se conserva.

Elías Tormo hace suya la lista de obras que facilitó el historiador y crítico de arte Joseph Théophile Thoré (seudónimo de W. Bürger) ${ }^{15}$. De ellas recogemos las siguientes que hacen referencias al tema que nos ocupa:

13 Ibídem.,11, pág. 262.

14 CEÁN BERMÚDEZ, J. A.: Diccionario histórico de los más ilustres profesores de las bellas artes en España. Madrid, Imp. Vda. de Ibarra, 1800, págs. 311-314.

15 TORMO: op. cit., 11, pág. 261. "Con estas reservas, supla la letra íntegra de Thoré por la mía, sobre todo por la circunstancia de que él escribió, no solo conociendo los Cerezos notables de los Museos de los paí- 


\section{Q: artículos Susana Fernández de Miguel}

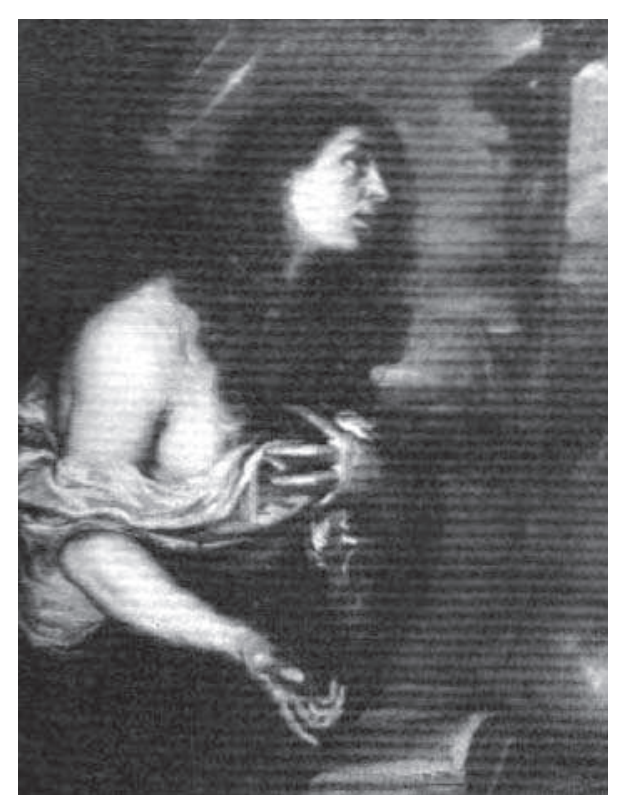

5. Magdalena Penitente, Colección Gamazo.

- "Magdalena penitente", de la Galería del Conde Czernin, en Viena, fechada en 1668 (1664).

- "Magdalena penitente", entonces del Museo de Berlín y hoy fuera del mismo, réplica de la anterior, en su tratamiento, aunque no en las proporciones.

- "Magdalena penitente", del Museo de La Haya. Núm. 206 del catálogo, a la que califica como casi análoga a la de Czernin, y que la considera como "mejor" que aquélla.

De manera personal cita las siguientes:

- "Dos Magdalenas" que tiene el Marqués de Salamanca, en su finca de Vista Alegre, cerca de Madrid.

- "Magdalena", del Museo del Ermitage en San Petersburgo, procedente de la venta del Conde de Gessler, cónsul ruso en Cádiz

Buendía-Gutiérrez Pastor incluyen, dentro del género que nos ocupa, como de la autoría de Mateo Cerezo las siguientes ${ }^{16}$, que tratamos según la cronología que se propone:

1.- Magdalena penitente. Rijksmuseum Ámsterdam ${ }^{17}$ [4].

Núm. 29 del Catálogo Buendía-Gutiérrez Pastor.

ó/l. 1,03 x 0,83 cm. Firmado y fechado: "Matheo Zereço fec.an.de/1661".

ses germánicos: La Haya, Cássel, Budapest (antes Esteráis, de Viena), Czernin (de Viena), Berlín (antes Suermondt, en Aquisgrán), sino porque conoció también, y ahora nosotros, los lienzos de las Colecciones Louis Philippe I, Standish, Soult, Aguado (Marqués de las Marismas, París) y José Madrazo, galerías hoy dispersadas". 


\section{2: artículos La Magdalena Penitente de Mateo Cerezo...}

Este cuadro fue adquirido en 1823 por el rey Guillermo I a Mme. Madeleine Dubourg, en París, y depositado después en el Mauritshuis de La Haya, donde permaneció hasta 1948 en que fue trasladado al Rijksmuseum de Ámsterdam. La pintura, perteneciendo ya a las colecciones holandesas, fue grabada en el siglo XIX por Lange en el Recueil, Steengracht, núm. 96, y en litografiado invertido por J. J. Hesker en 1872.

Está fechada en el mismo año que los "Desposorios" de la Catedral de Palencia y es una de las obras más conocidas de Mateo Cerezo y de las más cuidadas en su producción, por lo que ha sido siempre justamente alabada y citada por los autores como muestra álgida en la calidad de su pintura. Pertenece a sus primeros años madrileños, en los que, ya apartado de los modelos de Pereda, adopta el efecto esfumado, en una pintura caracterizada por la suavidad en el gesto del personaje y en los colores.

La pincelada es corta y su trazado esmerado, ayudada por la finura en la textura de los pigmentos. Su técnica es más ligera y transparente que en las obras siguientes. El dibujo, resultado de la pincelada y la técnica, se muestra esmerado y detallista. En los colores priman los azules, claros y fríos, y los dorados. El tratamiento y tonalidad de las encarnaduras es excelente, consiguiendo una textura casi táctil que acentúa la sensualidad de la representación.

Destacan, también, los tonos nacarados y brillantes de la camisa, que denotan la riqueza del ropaje y que contrasta con las franjas del tejido perfilados por el artista con profusos y voluminosos pliegues. Presenta a la santa en figura de medio cuerpo, semidesnuda, permitiendo la contemplación, a través de su camisa abierta, de los hombros y parte del pecho, que deja al descubierto. Su mirada, suplicante, aunque sin dramatismo, se abandona a la contemplación, concentrada en la visión del crucifijo, que se sitúa, de frente, junto a ella.

Por último, el paisaje aparece menos contrastado y más etéreo, que en otras réplicas de la santa.

La obra integra la representación de un abandono espiritual confiado y esperanzado, habiendo obtenido el artista una dulce y pacífica visión del éxtasis religioso. El repertorio colorista que el artista desarrolla, le permite obtener una mayor dulcificación de esta escena religiosa, a lo que contribuye también la naturaleza donde sitúa la acción. Mateo Cerezo utiliza para esta versión los atributos más usuales de la santa: la calavera, el libro y la naturaleza, además del cilicio y las raíces.

Si bien, no es una de sus obras más personales, en cuanto al lenguaje pictórico, por seguir otras tendencias técnicas preexistentes, sí podemos decir que es una bella representación de la santa, por la falta de dramatismo en su tratamiento.

Abunda también en esta opinión el historiador W. Bürger de la que afirmó que

\footnotetext{
16 BUENDÍA, J. R. y GUTIÉRREZ PASTOR, I.: op. cit., n 9, págs. 129-131.

17 RIJKSMUSEUM, Nacional Museum for Art and History. Ámsterdam, 2006. [publicación en línea] disponible desde Internet en: http://www.rijksmuseum.nl/collectie/zoeken/asset.jsp?id=SK-C-1347\&lang=en (con acceso el 29-12-2006)
} 


\section{Q: artículos Susana Fernández de Miguel}

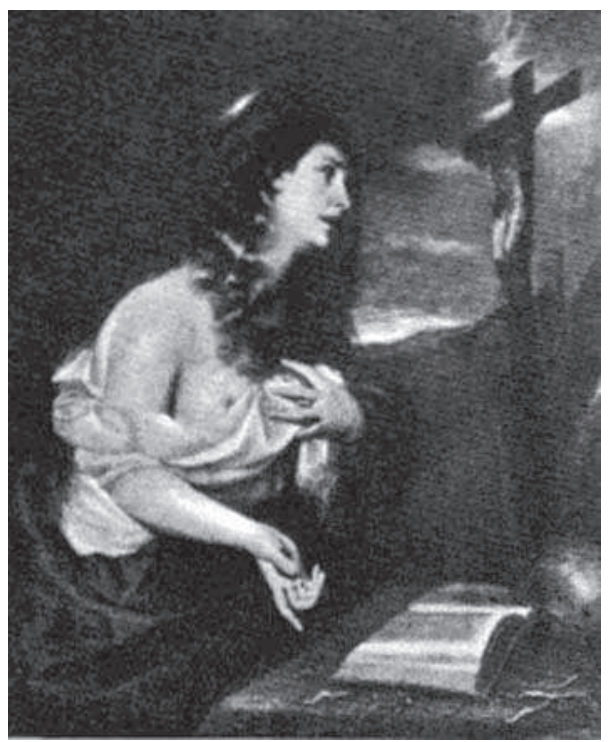

6. Magdalena Penitente, Colección Czernin. Viena.

era "una de sus pinturas más bellas"18. Recogen esta obra Gaya Nuño ${ }^{19}$, estando ya en el Rijksmuseum, y Camón Aznar20.

\section{2.- Magdalena penitente. Colección Gamazo. Madrid [5].}

Núm. 59 del Catálogo Buendía-Gutiérrez Pastor.

ó/l.

Buendía publicó esta obra en 1965, en la revista Goya21. Ya en la monografía del pintor, este autor alude a que, por la mayor densidad de los empastes, la pintura se corresponde, en su ejecución, con los años 1663-1665. Como diferencias, cita el envejecimiento del rostro, el acento en los sombreados, la ausencia de las franjas de seda en los ropajes de la santa y el mayor nerviosismo en el plegado de los paños.

La pintura, si bien es una réplica de la anterior, con algunas variantes, presenta más coincidencias estilísticas con la "Magdalena Penitente" de la Colección Beruete-Granados y está más cercana a ella en su datación, tanto por las características estilísticas de ambas obras, como por las técnicas.

Buendía-Gutiérrez Pastor sugieren la posibilidad de que esta obra se trate de la misma pintura que perteneció a la colección Beruete y que, desde allí habría pasado a la colección Gamazo22.

18 TORMO: op. cit., 11, pág. 263.

19 GAYA NUÑO, J. A.: La pintura española fuera de España. Madrid, 1958, pág. 134.

20 CAMON AZNAR, J.: La pintura española del siglo XII. "Summa Artis", Vol. XXV. Madrid, 1977, pág. 475.

21 BUENDÍA, J. R.: "Mateo Cerezo en su tercer centenario (1626-1666)", Goya, nº 71 (1965-1966), págs. 278-291. 


\section{2: artículos La Magdalena Penitente de Mateo Cerezo...}

Pérez Sánchez ${ }^{23}$, con referencia a esta misma obra, afirma que de ser la misma pintura que la de la colección Beruete, como planteaban Buendía-Gutiérrez Pastor, hubiera debido conservar la etiqueta de Recuperación.

Del resultado de nuestro estudio podemos concluir que la afirmación de Pérez Sánchez carecía totalmente de base, ya que la reaparición de la pintura de la "Magdalena" de Beruete, ha aclarado que carecía de esta etiqueta, por lo que este detalle no permite refutar fundamente la afirmación de Buendía-Gutiérrez Pastor. De ser cierta la afirmación de que, en esta pintura, la camisa de la Magdalena no presenta franjas en el tejido, habría que afirmar que son dos obras diferentes. Por nuestra parte, después de un estudio de ambas obras, hemos observado otras diferencias, que también exponemos y que permiten afirmar que se trata de dos réplicas diferentes, aunque las más similares en cuanto a su composición y ejecución técnica.

3.- Magdalena penitente. Colección Czermín. Viena [6].

Núm. 60 del Catálogo Buendía-Gutiérrez Pastor, ó/l. 1,00 x 0,80 cm.

Firmado y fechado "Matheo Zereço ft./año/1664".

Es una obra que se aleja algo más de las dos anteriores y supone, a nuestro entender, una réplica intermedia entre la de Beruete-Granados y la del Rijksmuseum, aunque menos acabada y cuidada que la primera. También pudiera tratarse que, una peor conservación de la pintura, haya barrido alguna de sus capas superiores, reduciendo la calidad, ahora apreciable. Las diferencias de esta réplica se sitúan en el escenario, que adquiere en ésta mayor amplitud, implicando un mayor alejamiento del crucifijo y de la mesa junto con los objetos sobre ella representados. Este alejamiento afecta también a la figura de la santa, su fisonomía, que es más similar a la del Rijksmuseum, por el contrario, mantiene el gesto, la simbología y el escenario natural de las demás réplicas.

\section{4.- Magdalena Penitente. Colección Beruete, hoy Colección Granados.}

Madrid, o/l 1,02 x 0,84 cm.

Es una réplica que difiere de la del Rijksmuseum, pero no desmerece en belleza y singularidad. En cuanto a tamaño coincide con los formatos de las otras representaciones.

22 BUENDÍA, J. R. y GUTIÉRREZ PASTOR, I.: op. cit., 9, pag. 151. "Probablemente se trata de la misma pintura que perteneció a la colección Beruete, citada por Buendía (Foto Mas G-19.509), de donde pasaría a la del conde de Gamazo (Foto Archivo Moreno 17.091/B)."

23 PÉREZ SÁNCHEZ : op. cit., 12, pág. 281.

"59.- Magdalena. Si, como parece esta Magdalena es la que perteneció a Beruete, debe conservar la etiqueta de Recuperación. Sus dimensiones eran $1,04 \times 0,83$. Resulta sorprendente -y testimonio de una cierta inconexión entre las diversas partes del libro, sin duda realizadas por separado-, el hecho de que, al estudiar (núm. 24) el ejemplar del Museo de Ámsterdam, se diga que este lienzo Beruete-Gamazo, es copia "interpretada con mayor bravura que Cerezo" y luego, bajo este número 59, se la considere réplica autógrafa y se la feche entre 1663-65 'por mayor densidad de los empastes". 


\section{Q: artículos Susana Fernández de Miguel}

Por las características pictóricas fechamos esta obra en un periodo posterior a la del Rijksmuseum y por lo tanto en 1665. A través de esta obra y en correspondencia con las anteriores, podemos apreciar la evolución estilística del pintor. Vemos cómo la pincelada se ha alargado, se ha hecho más vigorosa y más suelta. Ya no necesita una terminación más depurada para lograr el efecto deseado. La pintura se aboceta, los colores se oscurecen, se tornan menos fríos, más vivos e intensos y el dramatismo se acentúa. Contrasta más los colores, sobre todo los azules y los rojos, oscureciendo los dorados y acentuando el uso de los claroscuros. El tono de los labios aporta una nota de color, destacando el rostro de la santa. Los azules claros y tenues se han vuelto más vigorosos y los suaves dorados del cabello han dejado paso a los tonos castaños, sin apenas reflejos rubios. El tratamiento y tonalidad de las encarnaduras también ha variado, ya no se presentan con esa textura casi táctil y sensual, refleja más las de los ascetas penitentes, duras y secas, aunque no estén, en este caso, exentas de feminidad y belleza. Ha desaparecido el tornasolado, la jugosidad y el esfumado. La ligereza de la tela de la camisa que cubre a la santa también ha desaparecido, se ha hecho menos transparente y más gruesa. Ya no es seda, es más lienzo. Es menos mundana y más gravemente espiritual, sin embargo ha ganado en movimiento. Las franjas de la tela, aunque se distinguen perfectamente, han perdido importancia. La mirada también se dramatiza, ha desaparecido la contemplación confiada y esperanzada y se ha vuelto más suplicante.

El artista sigue representando a la santa en figura de medio cuerpo, dejando al descubierto la misma anatomía que en la primera de las réplicas citada. El empastado en la pincelada es más grueso en esta versión, con menos veladuras, más impresionista y de ejecución más rápida.

El repertorio colorista mantiene mayores similitudes con las obras realizadas en 1663, como el "San Juan Bautista" de Kassel o la "Impresión de las llagas de San Francisco de Asís" de Wisconsin. El paisaje que rodea a la santa mantiene la misma configuración, pero también se torna más oscuro y contrastado, todo para acentuar el dramatismo en la obra. La pintura progresa en un mayor abocetado de la representación y se aprecia como, a partir de ese momento, el artista abandona el prototipo carnoso y exuberante, para centrar su producción en la representación de la Magdalena penitente más teatral, ascética y dramática, en el periodo más próximo a su muerte.

Respecto de la misma réplica, la que nos ocupa mantiene pequeñas diferencias en la posición de la cabeza. La Magdalena de la Colección Granados presenta una superior y más acentuada inclinación lateral que la de la Colección Gamazo, en señal de mayor abandono espiritual y más intensidad en el sentimiento, con una mayor apertura de la mano que sitúa sobre el pecho, a la altura del corazón. También son apreciables pequeñas variaciones en el volumen del cabello, el cielo, la posición del crucifijo y las nubes 


\section{D. artículos La Magdalena Penitente de Mateo Cerezo...}

del fondo. En esta obra, al igual que en la Magdalena de la colección Gamazo, vemos materializada la evolución pictórica de Mateo Cerezo, que ha alcanzado su estilo más personal, caracterizando la madurez y plenitud de su pintura. Es una muy buena obra de Mateo Cerezo, que refleja los logros a los que llegó el artista y apunta los que hubiera podido alcanzar, si su pronta muerte, no hubiera truncado su carrera. Lo que es indudable es que este evento nos ha permitido constatar el número de réplicas existente de esta versión de la Magdalena, que se presentaba confusa en la bibliografía existente hasta ahora.

A la belleza intrínseca de la pintura se añade la curiosidad de sus avatares, mostrándonos cómo en un breve espacio de tiempo, la pintura viaja de España a Inglaterra, y regresa de nuevo a nuestro país, y, en el ínterin, acusa al menos el paso por tres diferentes propietarios y dos ventas públicas.

Es por ello que, cuando se produce la localización de una obra, como en este caso, sea necesario aprovechar la ocasión para completar su seguimiento y obtener una mejor documentación a efectos del aseguramiento futuro de un mejor conocimiento de nuestro patrimonio y riqueza artística y terminamos reiterando las palabras de Elías Tormo, que resumen perfectamente la importancia que Mateo Cerezo alcanzó en el mundo pictórico de su tiempo y de la repercusión de su obra en el panorama nacional :

“(...) fue tan excelente pintor como los más excelentes pintores de las escuelas españolas en los años primeros después de la muerte de Velázquez, acaso sin ceder la vez, sino por la prematura muerte, a ninguno de ellos...". "fue un devoto de la delicadeza, del primor, de la hechicera sutileza de lo femenino".

A esto, añadimos, que fue un artista excelente en su tiempo, celebrado después de su muerte y cuya obra ha traspasado su propia existencia. 
